Dogotari N. ${ }^{1,2}$, Gudumac Eva ${ }^{1}$, Tica C. ${ }^{2}$, Eremia V. ${ }^{1}$, Ionescu C. ${ }^{2}$, Babuci S. ${ }^{1}$

\title{
Clinical And Morphopathological Considerations In Pulmonary Hydatid Cyst Complicated By Endobronchial Rupture In Children
}

${ }^{1}$ State University of Medicine and Pharmacy "Nicolae Testemitanu", Chisinau, Republic of Moldova

${ }^{2}$ University "Ovidius" of Constanta, Faculty of Medicine

\begin{abstract}
The authors present a clinical case that aims to elucidate the diagnostic tactics and the efficiency of the chystostomy procedure performed in children with complicated endobronchial lung hydatid cyst and the potential serious postoperative complications that may occur in the case of this non-capitonary residual cavity technique after pulmonary echinococectomy.

Faced with the clinical, surgical and morphopathological investigations of the endobronchus ruptured lung hydatid cyst, the authors conclude that the spectra of morphological pathogenesis present in these cases are responsible for the development of persistent aerostatic disorder, resulting in a long-term postoperative morbidity, which confirms the need to optimize the methods of surgical correction of postechinococectomial residual cavities.
\end{abstract}

Keywords: chystostomy, residual cavities, echinococectomy, hydatid cyst.

Ionescu Constantin

Faculty of Medicine, Univeristy „Ovidius” of Constanta

Universitatii Alee No. 1, Campus B

Constanta, Romania

email : costin@anatomie.ro

phone: +40722802684

\section{Introduction}

Pulmonary hydatid cyst complicated by endobronchial or intrapleural (spontaneous or posttraumatic) rupture is a severe clinical-evolutive stage, developing a series of parenchymal or pleural complications. Infection and association of septic symptoms are the main clinical symptoms of patient's condition impairment $[1,2,3]$.

The rate of complications in case of pulmonary hydatid cyst rupture in children is lower than in adults, the incidence of intact cysts in children being 42.7 to $71.0 \%$, compared to 35.0 to $52.6 \%$ in adults, and the ratio of intact cysts is $3: 1[4,5,6,7]$. The progressive increase of pulmonary hydatid cyst may cause erosion of the adjacent bronchi, which initially, due to intracystic pressure and obliteration of bronchial communication does not function as fistula, causing endobronchial or intrapleural rupture of the cyst, with the development of pneumothorax or hydro-pneumothorax $[8,9]$.

The objectives of this work was to analyze the diagnostic act and surgical procedure of cystostomy applied to children with pulmonary hydatid cyst complicated by endobronchial rupture, efficiency feature of noncapitonnage technique and some 
potential complications that may occur in the postoperative period.

\section{Clinical case.}

Patient C., aged 16 years, from rural area, was hospitalized in the surgical intensive care unit CNŞPCP «Natalia Gheorghiu» on 3 Februry 2015, being transferred from the district hospital with liver and lung hydatidosis, and multiple trauma: craniocerebral trauma, cerebral concussion, parietooccipital linear fracture on the left, contusion of the lumbar region on the left and lung contusion (No. $\mathrm{f} / \mathrm{m}$ 1-3155).

On admission the patient's general condition was serious: general weakness, pronounced headache, pain in left costal margin and at the chest level, shortness of breath, wet cough with expectorations with white membrane fragments and hemoptysis. There was an insignificant heredo-colateral family history.

\section{History}

Three days before, being hit by an aggressor, the patient suffered from trauma to the chest and abdomen resulting in thoracic and abdominal pain, abundant watery and bloody vomiting. The day after the accident the general condition worsened and the patient was admitted to the district hospital.

The patient's condition at admission in the surgical intensive care CNŞPCP «Natalia Gheorghiu»: medium constitution, at general inspection a reduced excursion of the left hemithorax was recorded; auscultation revealed lack of breath in the lower lobe in the left lung, multiple wet crackles of different caliber and shallow breathing in the upper lobe and rough respiration in the right lung. The liver was protruding below the costal margin by $3 \mathrm{~cm}$. There were recorded normal heart sounds, the pulse being 80 beats/minute, blood pressure was $120 / 70 \mathrm{mmHg}$. Inspection of the abdomen found a swelling occupying the left epigastric region, left hypochondrium and partially the umbilical region.

The laboratory investigations showed: anemia, leukocytosis - 20,8x1091, increased ESR, C-reactive protein - $384 \mathrm{mcg} / \mathrm{ml}$, alanine amino transferase 16.0, aspartate aminotransferase -26.5 and creatinine $-106$.

Chest X-ray revealed a round volume formation in the upper lobe of the left lung, and a hydroaeric level formation in the lower lobe (Figure 1). Pulmonary perfusion scintigraphy showed an expressed diffuse attenuation of the circuit in the left lung, in the right lung the perfusion being intact (Figure 2). At ultrasound examination of the abdomen a cystic formation was detected $(89 \times 77 \mathrm{~mm})$ in the VI-VII segments of the liver, the diagnosis being also confirmed by computed tomography.

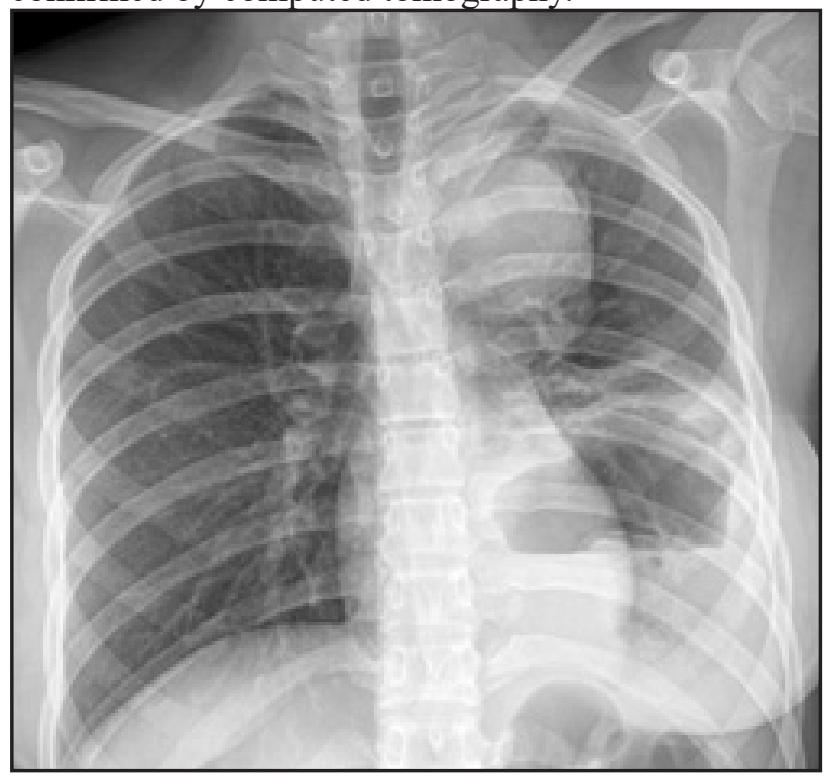

Figure 1 Chest $X$-ray of patient $C$., aged 16 years. A volume round formation localized in the upper lobe of the left lung and the other one with hydroaeric level in the lower lobe of the same lung are observed. Radiological sign of the floating membrane (sign of water lily) is observed 


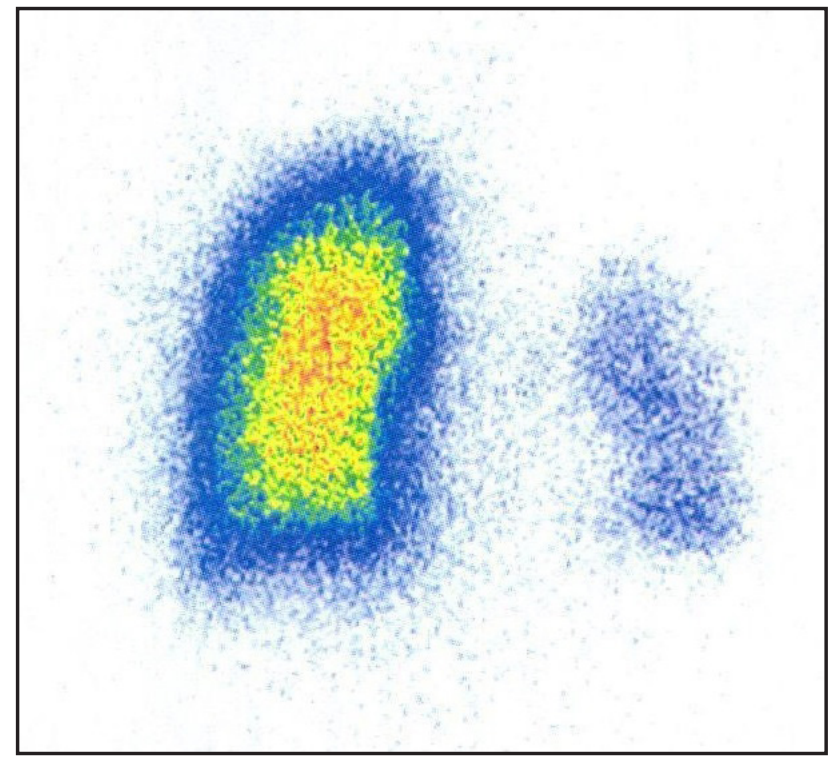

Figure 2 Pulmonary perfusion scintigraphy. Patient C., 16 years old. Hypoperfusion of the left lung

After the pre-operative preparation there were performed the latero-posterior thoracotomy on the left, echinococcectomy with scolicide cleansing of the residual cavities, partial capitonnage of the residual cavity of the upper lung lobe, pneumonostomy of the lower residual cavity and, finally, drainage of the pleural cavity and chest wall restoration.

The histopathologic examination revealed the presence of hyalinized pericystic tissue with alterative changes of diverse intensity with fascicularization aspects, in some areas having sinusoid appearance. The sinusoidal structures lined with granulocytic elements are more abundant in the pericapsular area forming a granulocyte layer, being followed by fibrinous alveolitis in mixture with granulocytes. The granulocyte component includes, in various ratio, eosinophilic elements (Figure 3,4).

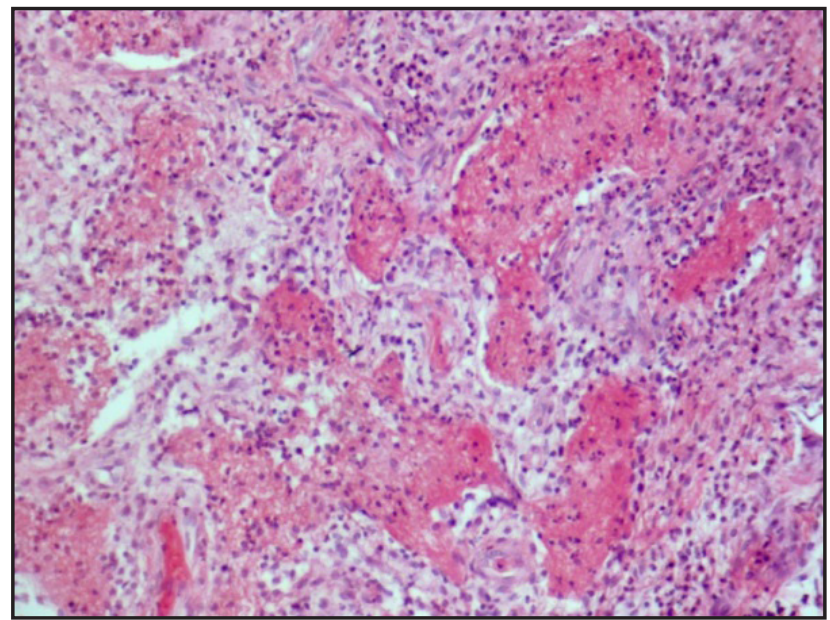

Figure 3 Fibrinous alveolitis mixed with granulocytes. $H$ \& E. $\times 175$

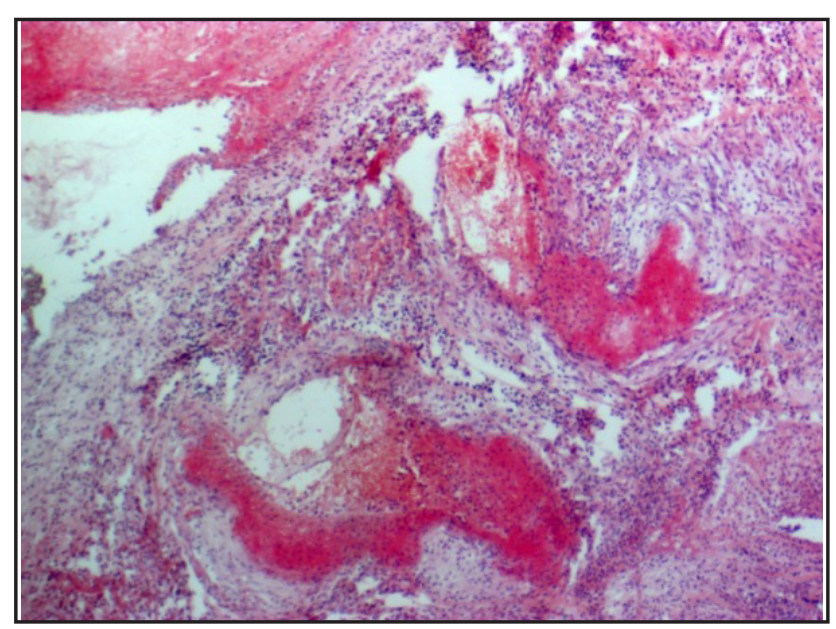

Figure 4 Stasis with aggregation phenomena, mixed thrombi and fibrinoid necrosis of the vessel wall. Color. $H \& E . \times 100$

In the postoperative period, after thoracic drain dysfunction, the patient's condition worsened, it being associated with compressive hydropneumothorax and collapse of residual lung segments with a massive subcutaneous emphysema of the chest extended on the neck and face (Figure 5). After restoring the drain functionality, there was stated a long persistence of the residual air leakage cavity, the follow-up complications and sequelae being objectified by the computed tomography (Figure 6,7). 


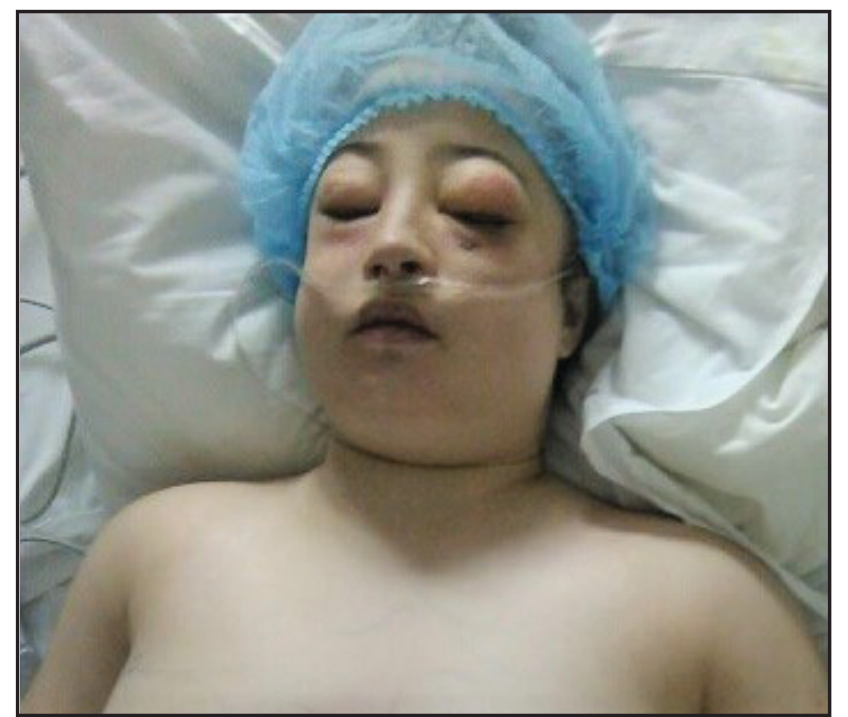

Figure 5 The appearance of patient $C$., aged 16 years, with subcutaneous emphysema of the chest, extending on the neck and face, on the 3rd day after surgery

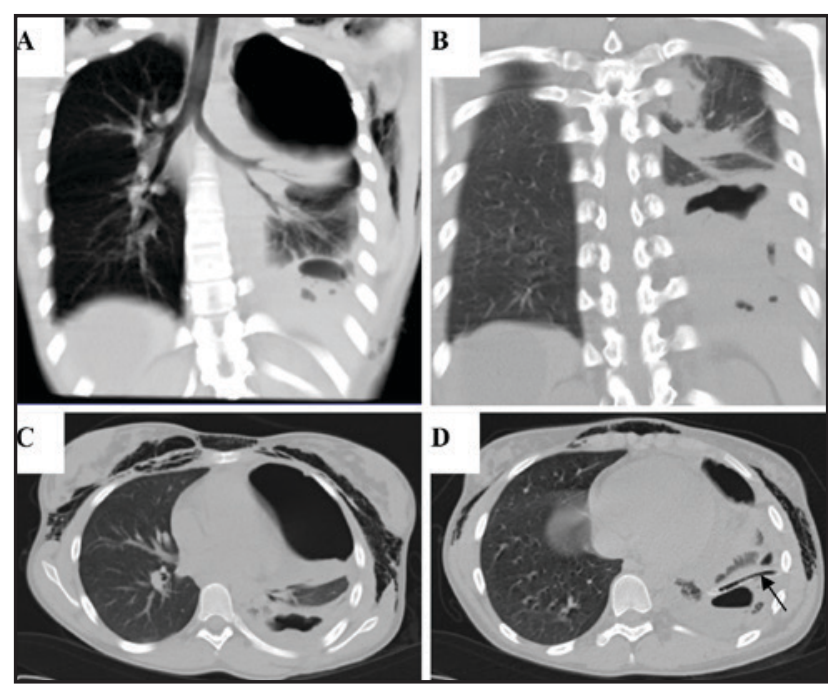

Figure 6 Patient $C$., aged 16 years. Spiral computed tomography carried out 32 days after surgery.

Hydropneumothorax on the left with collapse of the upper lobe of the left lung $(A, C)$. Air leakage cavity in the lower lobe S6/S10 of the left lung (A, B, C, D), which communicates with the bronchus lumen, segment 6.

Massive subcutaneous emphysema. The arrow indicates the chest drain path.

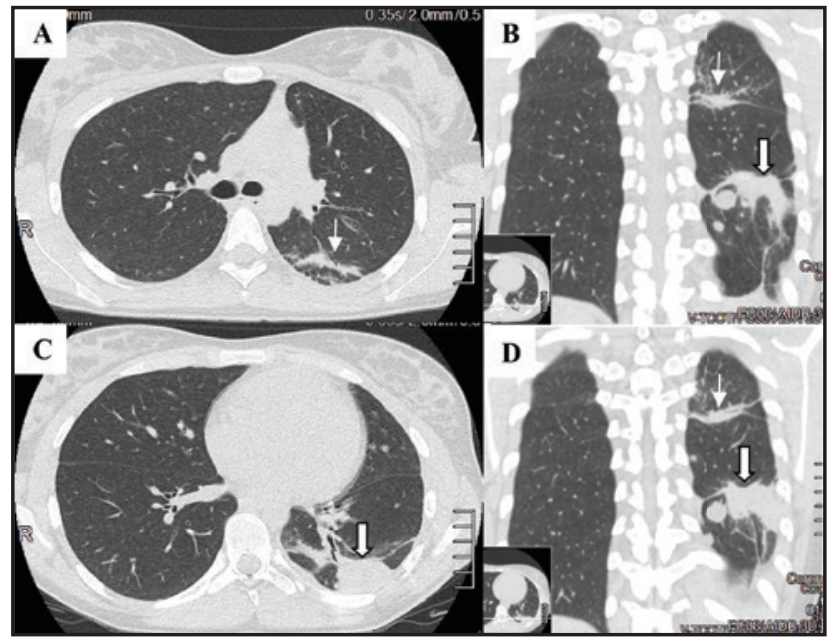

Figure 7 Patient C., 16 years old. Spiral computed tomography performed 9 months after surgery. A fine scar of the upper hydatid cyst area $(A, C, D)$ is observed, whose residual cavity was subjected to partial capitonnage (thin arrow), and X-ray appearance of the residual cavity without capitonnage $(B, C, D)$ (thick arrow)

The surgical treatment of hydatid liver cyst was performed in 3 months (18 June 2015) (No. f/m 2-4956) after resolving septic complications and removing pulmonary residual cavities (Figure 7). Static liver scintigraphy with Tc-99r FITON allowed to detect significant diffuse parenchymal changes and hepatosplenomegaly even after 6 months of liver echinococecctomy (Figure 8).

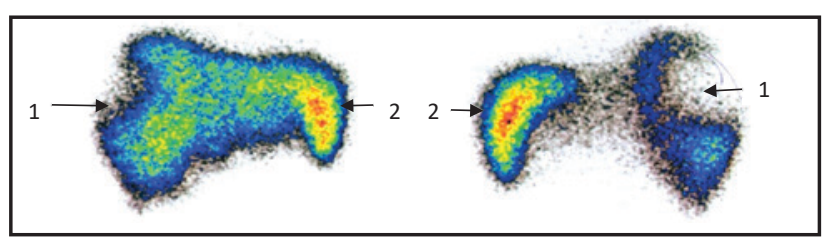

Figure 8 Patient C., 16 years old. Static liver scintigraphy performed 6 months after liver echinococecctomy. The liver typically located with shape changes, with clear and irregular contours, increased in size. Radiopharmaceutical spread is uneven. On the background of reduced accumulation of the preparation in the right lobe of the region of V, VI and VII segments it did not accumulate (1). The spleen increased in size with maximum preparation accumulation(2) 


\section{Discussions}

The development of pulmonary hydatid cyst may be aggravated by some associated complications that can cause serious clinical outcomes $[10,11]$. Pulmonary hydatid cyst rupture results in the release of antigenic material which causes immunological reactions along with the development of a generalized symptomatology of fever, acute hypersensitivity reactions [12,13], including anaphylactic shock and respiratory distress [11,14]. More often the rupture of pulmonary hydatid cysts occurs in the bronchial tree $(56.8 \%$ of the total number of complicated cases) than in the pleural cavity $(43.2 \%)[11,15]$.

Patients with pulmonary hydatid cyst complicated by endobronchial rupture have cough, shortness of breath, chest pain, expectorations with parasitic membrane fragments and hydatid fluid, persistent hemoptysis, productive sputum and fever [16]. Subsequent pulmonary hydatid cyst infection can result in total purulent destruction of the parasite $[9,17]$. Pulmonary hydatid cyst rupture into the pleural cavity (hydatidothorax) causes association of pneumothorax, extended pleurisy or empyema with the development of some fatal allergic and anaphylactic reactions $[17,18]$.

The cooexistence of pulmonary and hepatic hydatid cyst (hepatopulmonary hydatid cyst) is found in $7-18 \%$ of cases, and is an entity distinct from the disparate locations of hydatidosis, raising some problems of surgical treatment $[19,20]$. Hepatopulmonary hydatid cyst cumulates evolutive peculiarities of both forms of hydatid cyst (lung and liver), evolving for many years asymptomatically or with nonspecific manifestations, being diagnosed occasionally, either when some complications develop $[19,21]$ or with severe, potentially fatal symptoms [22]. The clinical manifestations of hepatopulmonary hydatid cyst can be polymorphic and depend mainly on the development phase of the parasite, the character of non-specific response of the body to the inoculated oncosphere, the growth rate, the number, the size and location of larvocysts, the associated complications.
The efficient resolving of residual cavities is of major importance in hydatid cyst surgery, especially in complicated forms. The noncapitonnage procedure applied to remove the residual cavities after echinococecctomy is shown by several authors as an alternative, as capitonnage does not shorten the hospitalization and duration of air removal through the chest tube and does not prevent complications such as empyema, the persistence of fistulas and air leakage, recurrence [23,24,25]. Closure and suturing of residual cavity edges are not required, the lung parenchyma removing the space and the lung surface at the site of residual cavity is covered by pleura. The noncapitonnage procedure of removing postechinococcectomic residual cavities is also supported in children [26].

The technique of creating a direct communication between the residual cavity and pleural space with the removal of bronchial fistulas and external drainage after removing hydatid metacestode was proposed by H. D. Yacoubian and T. Dajani (1963), being considered applicable in both the intact and complicated forms of lung hydatid cyst [31]. This idea was used by A.T. Pulatov when developing the technique for resolving residual cavities by the formation of some artificial interlobular or intersegmental fissures [27,28]. The method is intended to maintain the functionally uncompromised pericystic lung tissue, the efficacy and safety of this strategy having been described by several authors $[29,30]$. This procedure, called the «pneumonostomy» technique was also used in the treatment of lung abscess [31].

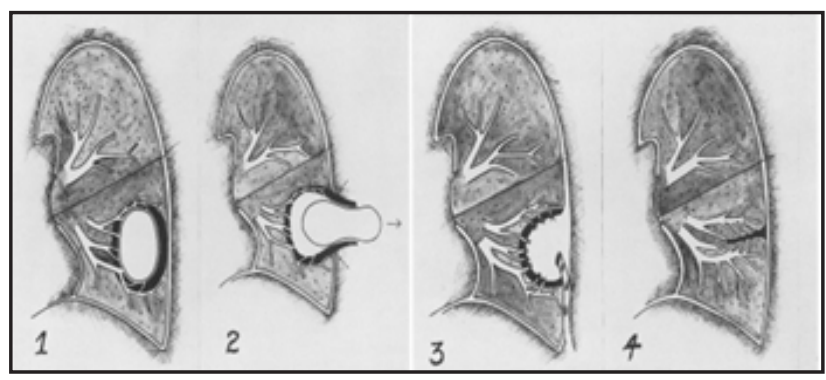

Figure 9 Graphical representation of the technique for resolving residual cavities after pulmonary echinococcectomy proposed by H. D. Yacoubian and T. Dajani (1963) 


\section{Conclusions}

Thus, confronting clinical and morphopathological aspects of pulmonary hydatid cyst complicated with endobronchial rupture allowed us to draw the following conclusions: 1. In pulmonary hydatid cyst complicated by endobronchial rupture in children there are some necrotic degeneration changes of the pericystic layer (fibrous capsule), with the development of the vascular thrombotic syndrome at the level of pericyst and adjacent lung parenchyma, and an acute granulocytic inflammatory process with eosinophilic component which can cause the development of persistent disorders of aerostasis.

2. In the pericystic parenchyma of pulmonary hydatid cyst complicated by rupture the pneumopathy is attested, manifested by fibrinous and fibrinousleucocytic alveolitis, and the pleural area is characterized by micropolypous inflammatoryproliferative mesothelial phenomena. These morphopathological manifestations cause a longterm postoperative morbidity.

3. These data, along with evolutionary aspects presented, confirm the need to optimize the methods of surgical removal of postechinococcectomic residual cavities in cases of pulmonary hydatid cyst complicated by rupture in order to reduce the postoperative morbidity and length of hospital stay, some major risks of developing serious complications being present in cases of a prolonged persistence of residual cavities.

\section{References:}

1. Bouchikh, M., Achir, A., Maidi, M., Ouchen, F., Fenane, H. \& Benosman, A. (2014). [Intrapleural rupture of pulmonary hydatid cysts]. Rev
Pneumol Clin, 70(4), 203-207. doi: 10.1016/j. pneumo.2013.12.006.

2. Fisher, J., Shargall, Y., Krajden, S., Moid, F. \& Hoffstein, V. (2011). Cystic echinococcosis: late rupture and complication of a stable pulmonary cyst. Can Respir J, 18(5), 258-260.

3. Ozdenir, T. \& Arikan, A. (2013). Pulmonary hydatid cyst rupture in childhood: presentation, diagnostic and treatment strategies. Turk. Arch. Ped. 48(4), 323-6.

4. Bagheri, R., Haghi, S.Z., Amini, M., Fattahi, A.S. \& Noorshafiee, S. (2011). Pulmonary hydatid cyst: analysis of 1024 cases. Gen Thorac Cardiovasc Surg, 59(2), 105-109. doi: 10.1007/ s11748-010-0690-z.

5. Bekci, T.T. (2012). Diagnosis and treatment of human hydatid disease. Eur. J. Gen. Med. 9(1), 15-20.

6. Dincer, S.I., Demir, A., Sayar, A., Gunluoglu, M.Z., Kara, H.V. \& Gurses, A. (2006). Surgical treatment of pulmonary hydatid disease: a comparison of children and adults. $J$ Pediatr Surg, 41(7), 1230-1236. doi: 10.1016/j. jpedsurg.2006.03.053.

7. Karavdic, K. \& Guska, S. (2011). Surgical treatement of pulmonary hydatid disease in children--a retrospective study. Med Arh, 65(1), 16-19.

8. Daghfous, H., Zendah, I., Kahloul, O. \& TritarCherif, F. (2014). Pleural complications of pulmonary hydatid disease. Tunis Med, 92(1), 6-11.

9. Puri, D., Mandal, A.K., Kaur, H.P. \& Mahant, T.S. (2011). Ruptured hydatid cyst with an unusual presentation. Case Rep Surg, 2011, 730604. doi: 10.1155/2011/730604.

10. Sayir, F., Cobanoglu, U. \& Sehitogullari, A. (2012). Surgical treatment of pulmonary hydatid cysts, which perforated to the pleura. Eurasian $J$ Med, 44(2), 79-83. doi: 10.5152/eajm.2012.19.

11. Shameem, M., Akhtar, J., Bhargava, R., Ahmed, Z., Khan, N.A. \& Baneen, U. (2011). Ruptured pulmonary hydatid cyst with anaphylactic shock and pneumothorax. Respir Care, 56(6), 863-865. doi: 10.4187/respcare.00821.

12. Kantarci, M., Onbas, O., Alper, F., Celebi, Y., Yigiter, M. \& Okur, A. (2003). Anaphylaxis due 
to a rupture of hydatid cyst: imaging findings of a 10-year-old boy. Emerg Radiol, 10(1), 49-50. doi: 10.1007/s10140-002-0265-0.

13. Michas, G., Varytimiadi, E., Varytimiadi, A., Toli, E., Kyriakopoulos, E., Michail, M. \& Vryonis, E. (2013). Pulmonary echinococcosis presenting as a pulmonary mass with chest pain, fever and non-productive cough. Arch. Hellenic Med. 30(2), 225-8.

14. Ozdemir, A., Bozdemir, S.E., Akbiyik, D., Daar, G., Korkut, S., Korkmaz, L. \& Bastug, O. (2015). Anaphylaxis due to ruptured pulmonary hydatid cyst in a 13-year-old boy. Asia Pac Allergy, 5(2), 128-131. doi: 10.5415/apallergy.2015.5.2.128

15. Sayir, F., Cobanoglu, U., Sehitogullari, A. \& Bilici, S. (2012). Our eight-year surgical experience in patients with pulmonary cyst hydatid. Int J Clin Exp Med, 5(1), 64-71.

16. Showkat, H., Sarmast, A., Amin, A., Mir, S., Kotwal, S., Parray, F., Lone, R., Arshad, F. \& Bakhshi, I. (2012). Hydatid lung cyst in a 5-yearboy presenting with prolonged fever. South African Journal of Child Health, 6(1), 23-25. doi:10.7196/SAJCH.348.

17. Kuzucu, A., Soysal, O., Ozgel, M. \& Yologlu, S. (2004). Complicated hydatid cysts of the lung: clinical and therapeutic issues. Ann Thorac Surg, 77(4), 1200-1204. doi: 10.1016/j. athoracsur.2003.09.046.

18. Joshi, J.M. (2011). Hydatidothorax. Lung India, 28(4), 315-316. doi: 10.4103/0970-2113.85745.

19. Diaconescu, S., Barbuță, O., Vascu B., Moscalu, C., Aprodu, G. \& Gavrilescu S. (2011). Coexistența chistului hidatic pulmonar cu cel hepatic. J. Chir, Iași, 7(2), 274-278.

20. Khurana, M.S., Narang, G.S., Ded, K.S. \& Kaur, L. (2012). Ruptured Hydatid cyst of lung. Curr. Pediatr. Res, 16(2), 156-8.

21. Anyfantakis, D., Blevrakis, E., Vlachakis, I. \& Arbiros, I. (2010). Hepatopulmonary hydatidosis in a ten-year-old girl: a case report. J Med Case Rep, 4, 205. doi: 10.1186/1752-1947-4-205.

22. Rinaldi, F., Brunetti, E., Neumayr, A., Maestri, M., Goblirsch, S. \& Tamarozzi, F. (2014). Cystic echinococcosis of the liver: A primer for hepatologists. World Journal of Hepatology, 6(5), 293-305. http://doi.org/10.4254/wjh.v6.i5.293
23. Erdogan, A., Ayten, A. \& Demircan, A. (2005). Methods of surgical therapy in pulmonary hydatid disease: is capitonnage advantageous? Aust. NZ J Surg. 2005, 75, 992-996.

24. Eren, M.N., Balci, A.E. \& Eren, S. (2005). Non-capitonnage method for surgical treatment of lung hydatid cysts. Asian Cardiovasc Thorac Ann, 13(1), 20-23. doi: 10.1177/021849230501300105.

25. Turna, A., Yilmaz, M.A., Haciibrahimoglu, G., Kutlu, C.A. \& Bedirhan, M.A. (2002). Surgical treatment of pulmonary hydatid cysts: is capitonnage necessary? Ann Thorac Surg, 74(1), 191-195.

26. Celik, M., Senol, C., Keles, M., Halezeroglu, S., Urek, S., Haciibrahimoglu, G., Ersev, A.A. \& Arman, B. (2000). Surgical treatment of pulmonary hydatid disease in children: report of 122 cases. J Pediatr Surg, 35(12), 1710-1713. doi: 10.1053/jpsu.2000.19219.

27. Пулатов, А.Т., Петлах, В.И. \& Карасева, О.В. (2001). Об эхинококкозе верхней доли легкого у детей. Детская хирургия, 3. С.8-12.

28. Пулатов, А.Т. \& Абдуфатаев, Т.А. (1994). Эхинококкэктомия верхней доли легкого у детей. Хирургия, 8, С.12-5.

29. Anand, V., Sen, S., Jacob, R., Chacko, J., Zachariah, N., Thomas, G. \& Mammen, K.E. (2001). Pneumonostomy in the surgical management of bilateral hydatid cysts of the lung. Pediatr Surg Int, 17(1), 29-31. doi: 10.1007/ s003830000439.

30. Jehangir, S., Kurian, J.J., Jacob, T.J., Gurram, G.M., Thomas, R.J., Mathai, J. \& Karl, S. (2017). Pneumonostomy in the Surgical Management of Hydatid Cyst of the Lung. Eur J Pediatr Surg, 27(2), 171-176. doi: 10.1055/s-0036-1580701.

31. Lacey, S.R. \& Kosloske, A.M. (1983). Pneumonostomy in the management of pediatric lung abscess. Journal of pediatric surgery, 18(5), 625-627. 